Review began 02/28/2022 Review ended 03/06/2022 Published 03/08/2022

๑) Copyright 2022

Mahmoud et al. This is an open access article distributed under the terms of the Creative Commons Attribution License CCBY 4.0., which permits unrestricted use, distribution, and reproduction in any medium, provided the original author and source are credited.

\section{Rare but Fatal Pasteurella multocida Infective Endocarditis: A Case Report and Literature Review

\author{
Mohamed Mahmoud ${ }^{1}$, Khadija El Kortbi ${ }^{2}$, Mohamed I. Abdalla ${ }^{3}$, Sheila Habib ${ }^{3}$
}

1. Internal Medicine, University of Texas Health Science Center at San Antonio, San Antonio, USA 2. General Practice, Hassan II University, Faculty of Medicine, Casablanca, MAR 3. Critical Care, University of Texas Health Science Center at San Antonio, San Antonio, USA

Corresponding author: Mohamed Mahmoud,mahmoud@uthscsa.edu

\section{Abstract}

Pasteurella multocida is a small Gram-negative organism that usually causes a localized infection after exposure to cat or dog scratches, bites, or licking wounds. Invasive infections, such as bacteremia and endocarditis, are very rare yet serious conditions that are associated with high morbidity and mortality, particularly in patients with major comorbidities. Here, we report a case of a 47-year-old male who presented to the hospital with altered mental status two weeks after a fall and was found to have a subarachnoid hemorrhage. Further workup revealed Pasteurella multocida bacteremia and infective endocarditis. The patient had a complex hospital course with septic shock and acute congestive heart failure with poor clinical outcomes. A comprehensive review of the literature of all reported cases of definite Pasteurella endocarditis follows.

Categories: Cardiology, Internal Medicine, Infectious Disease

Keywords: septic emboli, heart failure, dogs, cats, septic shock, liver disease, infective endocarditis, pasteurella spp, pasteurella multocida

\section{Introduction}

Pasteurella multocida (P. multocida), a small, Gram-negative, nonmotile coccobacillus, is a normal commensal of many animals' oral flora, with cats and dogs representing the majority [1]. It can cause a variety of infections in humans, most commonly skin and soft tissue infections, following scratches, bites, or licking wounds [1]. However, invasive infections, such as bacteremia and infective endocarditis (IE), are very rare though serious conditions that are associated with high morbidity and mortality, especially in patients with major comorbidities [2]. Here, we report a case of a 47-year-old male with liver cirrhosis and diabetes found to have $P$. multocida bacteremia and endocarditis. His hospital course was complicated by septic shock, hypoxemic respiratory failure requiring intubation, septic emboli to the brain, and multiple organ failure, ultimately resulting in death.

\section{Case Presentation}

Our patient is a 47-year-old male with a history of alcohol abuse, alcoholic liver cirrhosis, hypertension, and type 2 diabetes mellitus who presented with altered mental status. Per the patient's wife, his deterioration began after a fall in the shower two weeks before presentation, followed by progressively worsening headache and multiple episodes of epistaxis. His condition continued to deteriorate and 12 hours before presentation, he developed confusion, weakness, and agitation, which prompted his presentation to the emergency department (ED).

In the ED, his vital signs were as follows: temperature $37.2^{\circ} \mathrm{C}$, heart rate $99 / \mathrm{min}$, respiratory rate $20 / \mathrm{min}$, blood pressure 115/66 mmHg, and oxygen saturation 99\% on room air. On physical exam, he was illappearing, confused, and responding to painful stimuli only, with a Glasgow Coma Scale of 10. Skin examination was pertinent for jaundice, spider nevi, scattered ecchymoses, purpura, and scratch marks to his left lateral leg. Cardiac examination was normal except for tachycardia. Lungs were clear to auscultation, and abdominal examination was benign. The patient had +2 bilateral lower extremity pitting edema more prominent in the left side. Table 1 summarizes initial workup findings, and Figure 1 shows initial CT findings. 


\begin{tabular}{|c|c|c|c|c|c|}
\hline Lab & Result & Reference Range \& Units & Lab & Result & Reference Range \& Units \\
\hline $\begin{array}{l}\text { White Blood Cell } \\
\text { Count }\end{array}$ & 23.49 & $(3.40-10.40) \mathrm{K} / \mathrm{mcL}$ & D-Dimer & 7424 & $<500 \mathrm{ng} / \mathrm{mL}$ \\
\hline $\begin{array}{l}\text { Neutrophils } \\
\text { Absolute }\end{array}$ & 18.54 & $(1.50-6.60) \mathrm{K} / \mathrm{mcL}$ & Fibrinogen & 437 & $(152-445) \mathrm{mg} / \mathrm{dL}$ \\
\hline Hemoglobin & 10 & Male: (12.8-17.1) g/dL & C-Reactive Protein & 239 & $(0-10) \mathrm{mg} / \mathrm{L}$ \\
\hline Hematocrit & 28.9 & Male: (38.6-52.1) \% & Lactic Acid & 4.1 & $(0.5-2) \mathrm{mmol} / \mathrm{L}$ \\
\hline Platelets & $<9$ & $(140-377) \mathrm{K} / \mathrm{mcL}$ & Ammonia & 22 & $(11-32) \mathrm{mcmol} / \mathrm{L}$ \\
\hline Sodium & 127 & $(135-145) \mathrm{mmol} / \mathrm{L}$ & Troponin I & 0.027 & $<0.051 \mathrm{ng} / \mathrm{mL}$ \\
\hline Potassium & 3.8 & $(3.5-5.1) \mathrm{mmol} / \mathrm{L}$ & BNP & 90 & $<100 \mathrm{pg} / \mathrm{mL}$ \\
\hline Chloride & 90 & $(94-106) \mathrm{mmol} / \mathrm{L}$ & Urine Analysis with & ieflex Microscc & \\
\hline $\begin{array}{l}\text { Blood Urea } \\
\text { Nitrogen }\end{array}$ & 102 & $(7-25) \mathrm{mg} / \mathrm{dL}$ & Color & Dark Yellow & Straw, Pale yellow, Dark yellow \\
\hline Creatinine & 4.02 & Male: $(0.60-1.30) \mathrm{mg} / \mathrm{dL}$ & Appearance & Cloudy & Slightly cloudy, Clear, Hazy \\
\hline Glucose & 20 & $(60-100) \mathrm{mg} / \mathrm{dL}$ & Glucose & Negative & Negative \\
\hline AST & 26 & Male: < 35 U/L & Protein & Trace & Negative-Trace \\
\hline ALT & 51 & Male: < 46 U/L & Bilirubin & 2 & Negative \\
\hline Total Bilirubin & 4.6 & $(0.2-1.2) \mathrm{mg} / \mathrm{dL}$ & Ketones & Negative & Negative \\
\hline $\begin{array}{l}\text { Alkaline } \\
\text { Phosphatase }\end{array}$ & 816 & $(45-117) \mathrm{U} / \mathrm{L}$ & Specific gravity & 1025 & $(1001-1035)$ \\
\hline Total Protein & 5.4 & $(6.2-8.1) \mathrm{g} / \mathrm{dL}$ & Leukocyte esterase & 1 & Negative \\
\hline Albumin & 1.5 & (3.2-5) g/dL & Blood & Negative & Negative-Trace \\
\hline INR & 1.5 & $(0.8-1.2)$ & Nitrites & Positive & Negative \\
\hline Imaging/Test & & \multicolumn{4}{|l|}{ Findings } \\
\hline Chest X-ray & & \multicolumn{4}{|c|}{ Bibasilar atelectasis and superior mediastinal prominence concerning for adenopathy or mass (Figure 2A). } \\
\hline $\begin{array}{l}\text { CT head without I } \\
\text { contrast }\end{array}$ & & \multicolumn{4}{|c|}{$\begin{array}{l}\text { Left frontal hyperdense focus concerning for subarachnoid hemorrhage (Figure 1C) and nondisplaced right } \\
\text { nasal bone fracture. }\end{array}$} \\
\hline $\begin{array}{l}\text { CT chest without I } \\
\text { contrast }\end{array}$ & & \multicolumn{4}{|c|}{$\begin{array}{l}\text { Trace bilateral pleural effusion with compressive atelectasis and minimally displaced anterior wedge } \\
\text { compression deformity of the superior endplate of T3 without significant height loss. }\end{array}$} \\
\hline $\begin{array}{l}\text { CT abdomen and } \\
\text { without IV contrast }\end{array}$ & pelvis & \multicolumn{4}{|c|}{$\begin{array}{l}\text { liver cirrhosis with sequelae of portal hypertension including splenomegaly and portosystemic varices, small } \\
\text { hiatus hernia, and cholelithiasis without CT evidence of acute cholecystitis. }\end{array}$} \\
\hline $\begin{array}{l}\text { CT left lower extre } \\
\text { without IV contrast }\end{array}$ & & \multicolumn{4}{|c|}{$\begin{array}{l}\text { Stranding within the subcutaneous soft tissues predominantly along the anteromedial aspect of the tibia and } \\
\text { the posterolateral lower third of the femur is most suggestive of cellulitis (Figures 1A, 1B). }\end{array}$} \\
\hline $\begin{array}{l}\text { Bilateral lower extr } \\
\text { Doppler ultrasoun }\end{array}$ & remity & \multicolumn{4}{|c|}{ Negative for deep venous thrombosis. } \\
\hline ECG & & \multicolumn{4}{|c|}{$\begin{array}{l}\text { Normal sinus rhythm with premature atrial complexes, left axis deviation, and incomplete left bundle branch } \\
\text { block. }\end{array}$} \\
\hline 30 minutes EEG & & \multicolumn{4}{|c|}{ Evidence of mild to moderate encephalopathy with no seizure activity. } \\
\hline
\end{tabular}

TABLE 1: Initial workup including labs, imaging, electrocardiogram (ECG), and 30-minute electroencephalogram (EEG) findings

ALT: alanine aminotransferase, AST: aspartate aminotransferase, BNP: B-type natriuretic peptide, INR: international normalized ratio 


\section{Cureus}
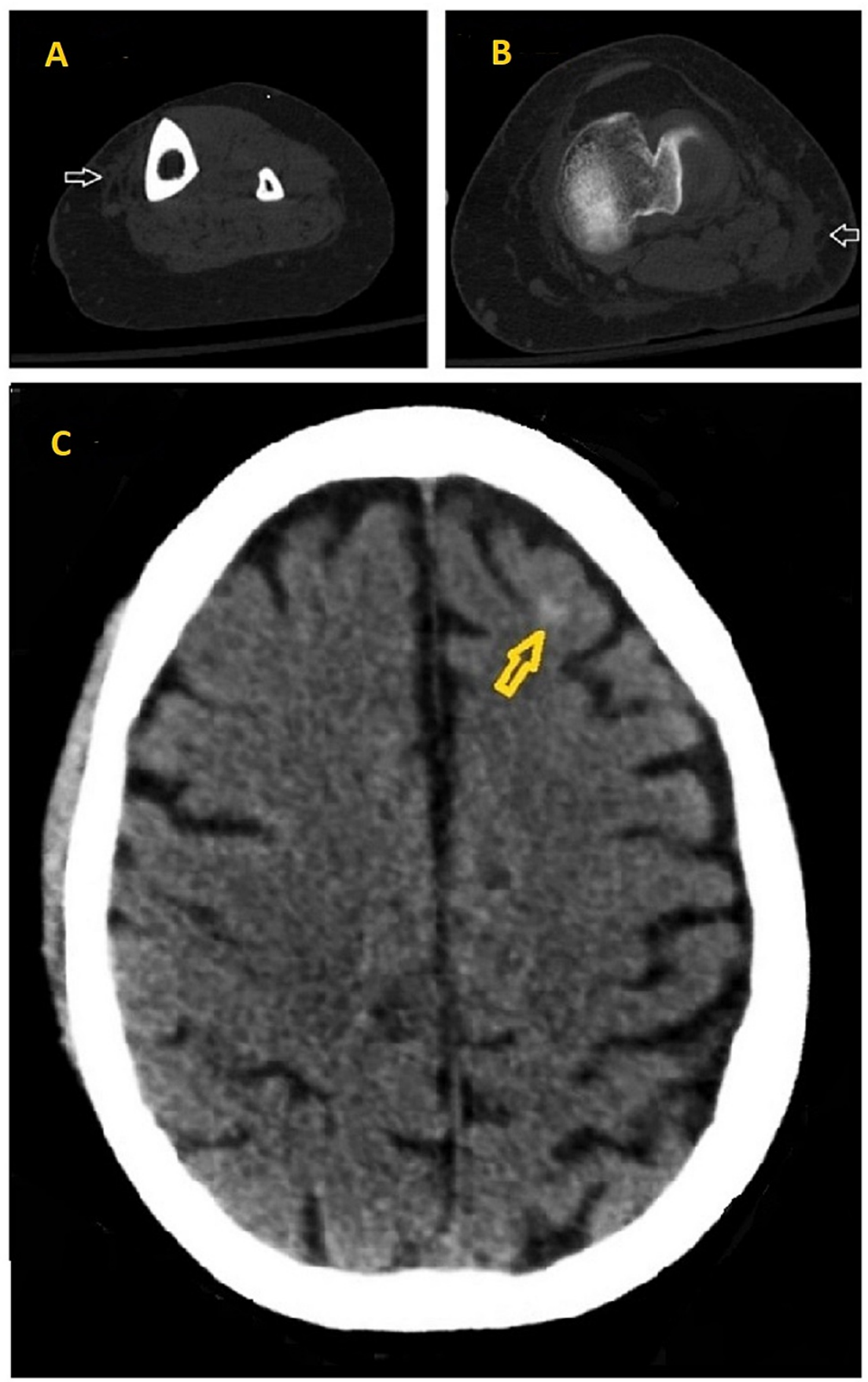

\section{FIGURE 1: Initial CT findings}

1A, 1B: CT left lower extremity showing stranding (white arrows) in the subcutaneous fat overlying the

anteromedial aspect of the tibia and the posterolateral lower third of the femur respectively. 1C: CT head without IV contrast showing left frontal subarachnoid hemorrhage (yellow arrow). 


\section{Cureus}
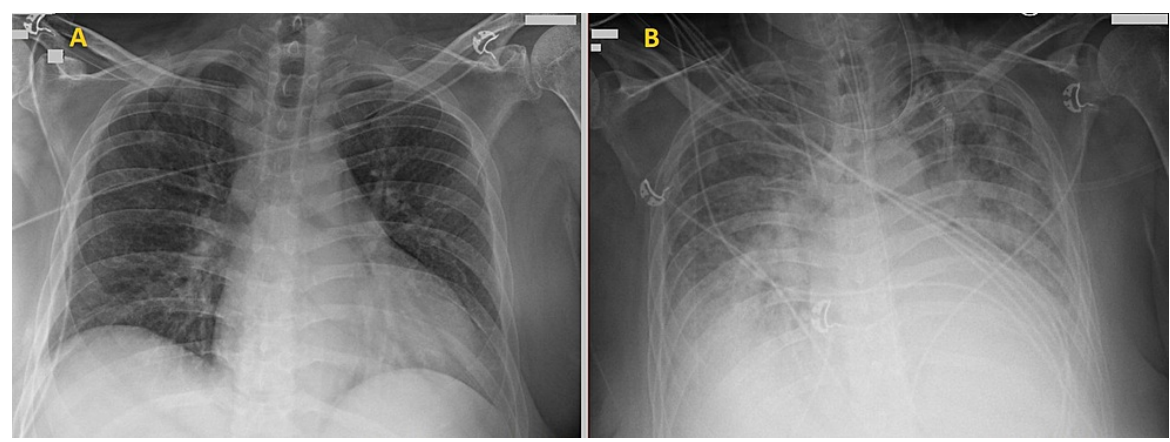

\section{FIGURE 2: Chest X-ray on admission and two days later}

2A: Chest $X$-ray on admission showing bibasilar atelectasis and superior mediastinal prominence concerning for adenopathy or mass. Two days later (Figure 2B), new moderate pulmonary edema developed.

The patient received intravenous (IV) fluids and platelet transfusion, resulting in improved creatinine to $3.31 \mathrm{mg} / \mathrm{dL}$, platelets to $22 \mathrm{~K} / \mathrm{mcL}$, and lactic acid to $1.8 \mathrm{mmol} / \mathrm{L}$. He was then admitted to the Medical Intensive Care Unit (MICU) and started on IV vancomycin and cefepime for sepsis. Two sets of blood cultures grew Gram-negative rods 11 hours after collection. Identification of P. multocida was done using matrix-assisted laser desorption/ionization time-of-flight mass spectrometry (MALDI-TOF MS). The disk diffusion test revealed susceptibility to penicillin, ampicillin, ceftriaxone, and levofloxacin. Urine culture was negative for any bacterial growth. Further questioning of the patient's wife revealed a history of scratch by an outdoor cat to his left leg two weeks before presentation.

Two days later, the patient developed tachypnea, tachycardia, and increased work of breathing. Chest X-ray showed increased infiltrates concerning for moderate pulmonary edema (Figure $2 B$ ) that was not found on the initial chest X-ray (Figure 2A). He was intubated and started on vasopressors for septic shock. Transthoracic echocardiogram (TTE) revealed a $1.5 \mathrm{~cm} \mathrm{x} 1.3 \mathrm{~cm}$ vegetation attached to the posterior leaflet of the mitral valve (Figures 3A, 3B), severe mitral regurgitation (MR) (Figure 3C), and an estimated left ventricular ejection fraction (LVEF) of $61 \%$. 


\section{Cureus}
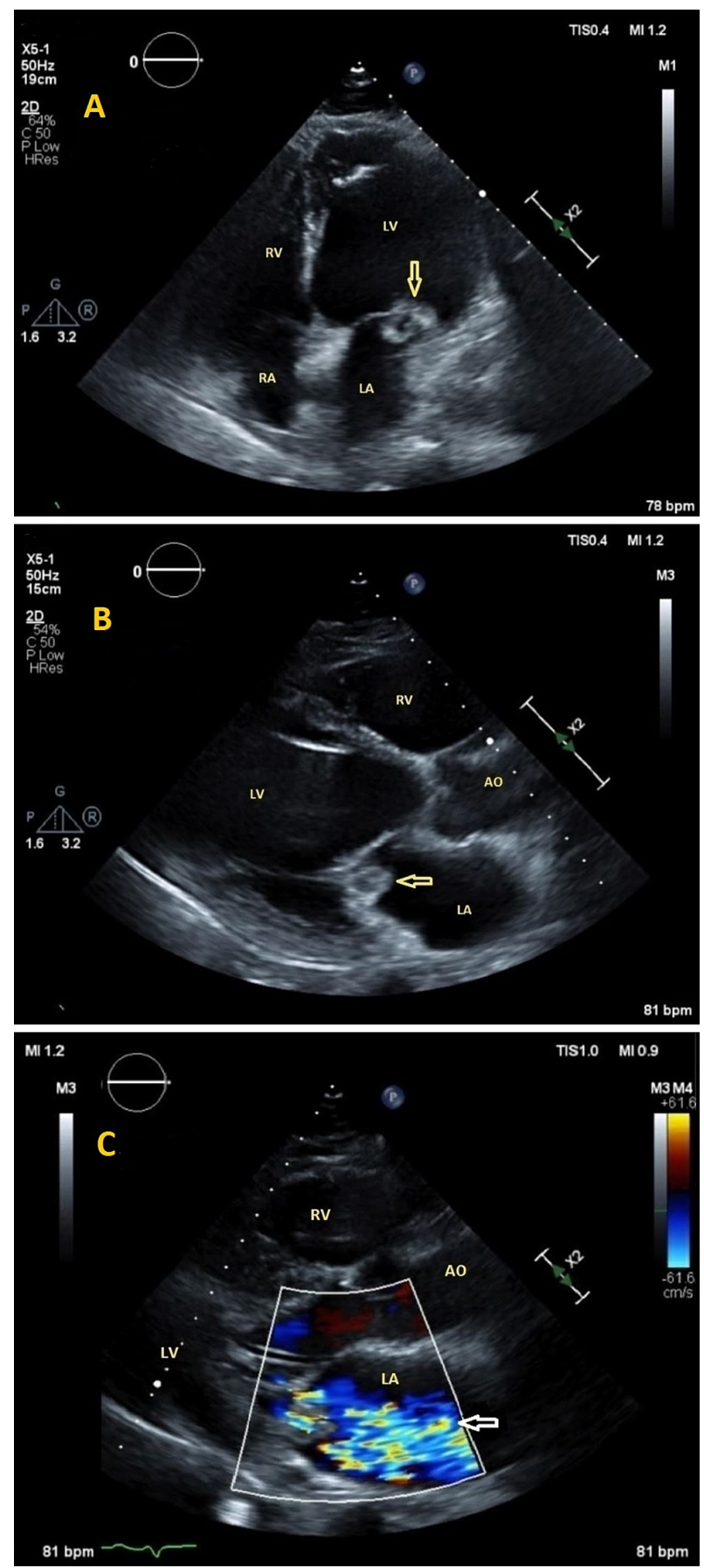

\section{FIGURE 3: Transthoracic echocardiography}

3A (apical 4 chamber view) and 3B (parasternal long-axis view) show a rounded irregular mass with a lucent center attached to the posterior leaflet of the mitral valve consistent with vegetation (yellow arrows), and a severely dilated left ventricle. $3 \mathrm{C}$ : Color Doppler showing severe mitral regurgitation (white arrow).

Repeat blood culture the next day was negative. Antibiotics were switched to IV ceftriaxone $2 \mathrm{gm} \mathrm{q} 12 \mathrm{hr}$ and IV metronidazole $500 \mathrm{mg}$ q $8 \mathrm{hr}$ to cover for possible meningitis and aspiration pneumonia given his

worsening mentation. Four days after admission, brain MRI showed signs of subacute lacunar infarcts with distribution suggestive of embolic phenomena (Figure 4). Spine MRI was negative for osteomyelitis, discitis, or spinal abscess. Cardiothoracic surgery was consulted and recommended repeating a TTE in one week. The patient was deemed a poor surgical candidate for surgical mitral valve replacement given his high MELD Na of 29, Child C liver cirrhosis, and subarachnoid hemorrhage. 


\section{Cureus}
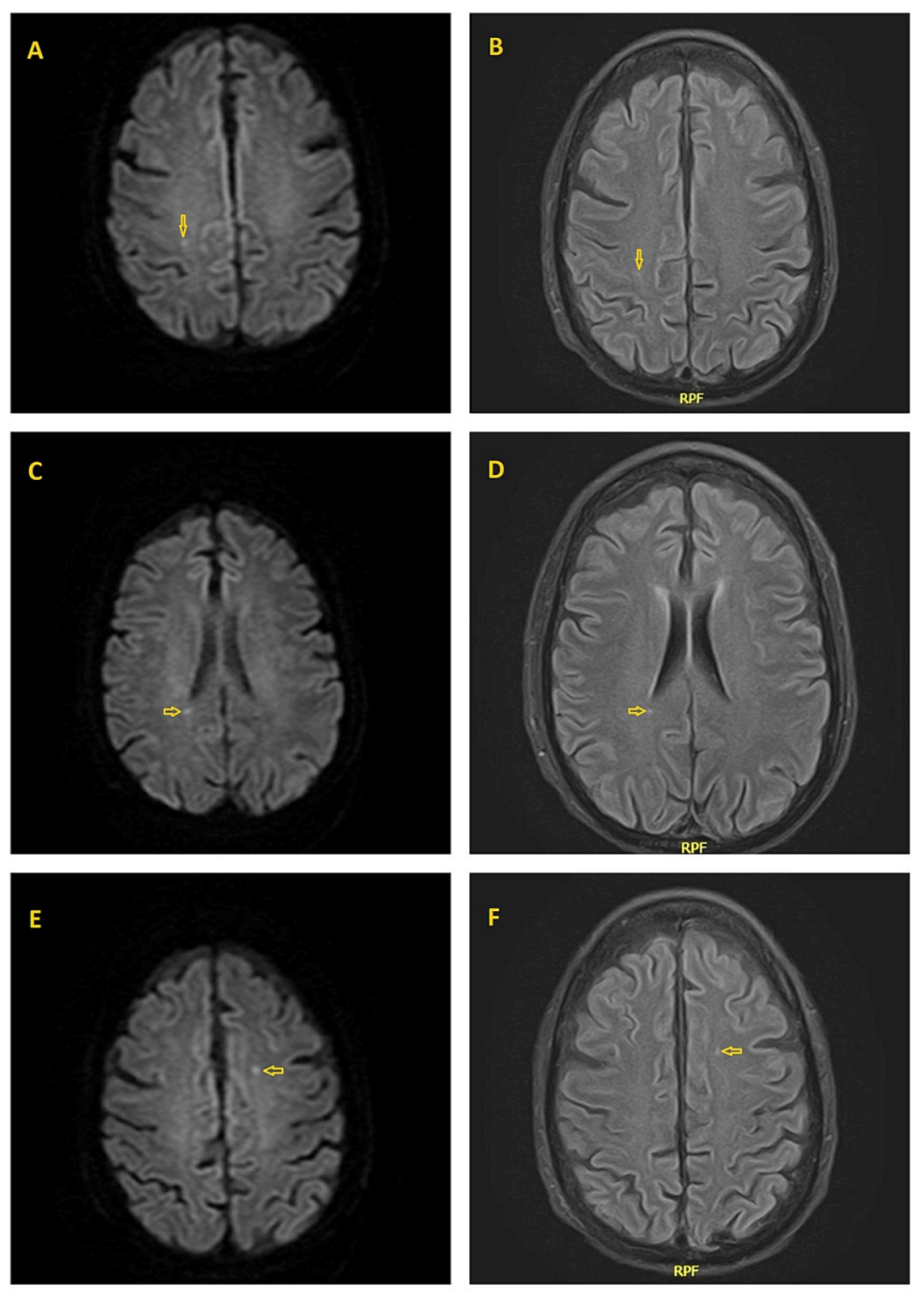

\section{FIGURE 4: Magnetic resonance imaging (MRI) of the brain}

Diffusion-weighted MRI (4A, 4C, 4E) and fluid-attenuated inversion recovery (FLAIR) MRI (4B, 4D, 4F) of the brain showing subacute lacunar stroke (yellow arrows) with distribution suggestive of embolic phenomena.

Three days later, the patient was extubated, following commands, and off vasopressors. He was then transferred to the medicine floor. However, after a few days, he developed severe pulmonary edema requiring bilevel positive airway pressure (BiPAP). Furthermore, he developed intermittent fever and anemia requiring blood transfusion. Physical exam was pertinent for diffuse anasarca, a blowing systolic murmur best heard at the lower left sternal border, and diffuse crackles bilaterally. B-type natriuretic peptide (BNP) was $1200 \mathrm{pg} / \mathrm{mL}$ and troponin I $0.22 \mathrm{ng} / \mathrm{mL}$. ECG showed sinus tachycardia and was negative for acute ischemic changes. CT pulmonary embolism (PE) study was negative for PE but showed marked worsening bilateral infiltrates, bilateral moderate to large pleural effusions, and right heart chamber predominant cardiomegaly. The patient was started on bumetanide drip $1 \mathrm{mg} / \mathrm{hr}$ and antibiotics were switched to IV vancomycin and piperacillin-tazobactam to cover for healthcare/ventilator-associated pneumonia. He was then transferred to the MICU and was re-intubated.

A repeat TTE revealed an increase in the size of mitral valve vegetation to $2.2 \mathrm{~cm}$ x $1.5 \mathrm{~cm}$. The MICU course was complicated by anemia and hemoptysis concerning for diffuse alveolar hemorrhage requiring blood transfusion; however, while receiving blood, the patient developed worsening oxygenation likely due to severe MR caused by the enlarging vegetation and volume overload. Blood transfusion was held, and the patient's diuretic regimen was increased. 


\section{Cureus}

Unfortunately, the patient's mental status did not improve and given his multiple comorbidities precluding him from aggressive interventions and prolonged complicated hospital course, his family decided to pursue comfort measures. He was palliatively extubated and transferred to the inpatient hospice service where he eventually passed comfortably.

\section{Discussion}

Pasteurella species (spp) are normal commensals of many animals' oral bacterial flora, primarily cats and dogs [1]. Human infection by Pasteurella usually causes localized skin and soft tissue infections [1]. However infective endocarditis is rare, with only 42 cases, including ours, reported in the literature. A PubMed search was conducted using keywords "Pasteurella" and "endocarditis". Only cases that met the Modified Duke infective endocarditis criteria [3] and with microbiologically proven Pasteurella infection were included and reviewed manually. Further studies were identified from the references of the selected cases. The number of reported cases has been increasing, especially in the last two decades (Figure 5). Males were affected more than females, comprising $62 \%$ of the reported cases. The mean age was $56.7 \pm 16.5$, ranging from 17 to 88 years. Table 2 summarizes the literature review of all reported cases of definite Pasteurella endocarditis. Table 3 shows a detailed review of all cases.

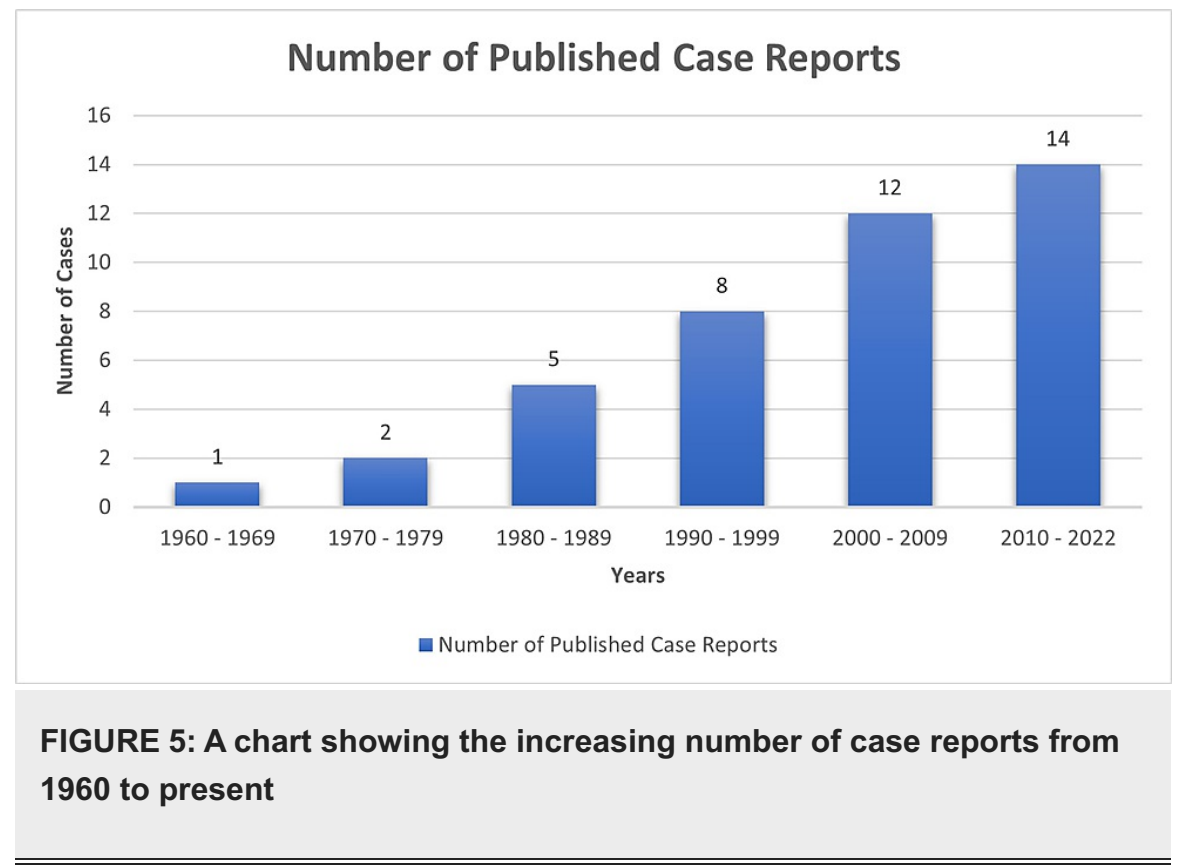

\section{Variables}

Number of Cases (\%) $\mathrm{N}=42$

Age (mean $\pm S D$ ) years

$(56.7 \pm 16.5)$

$<35$ years

35-70 years

$>70$ years

\section{Gender}

Male

Female

Unspecified

Location

USA

France

Japan

UK

Saudi Arabia

Others (countries that reported 1 case only) 


\section{Cureus}

Risk Factors

Substance Abuse (Smoking, Alcohol, or IVD)

$10(24 \%)$

Liver Disease

$7(17 \%)$

Heart Disease

$20(48 \%)$

Previous Endocarditis

$4(10 \%)$

Diabetes Mellitus

$2(5 \%)$

Solid Organ Transplant

$1(2 \%)$

Immunosuppressive Therapy

$1(2 \%)$

Cancer

Healthy With No PMH

$6(14 \%)$

Pasteurella Spp

Multocida

$29(69 \%)$

Non-Multocida Spp

$11(26 \%)$

P. Haemolytica

$3(7 \%)$

P. Dagmatis

P. Pneumotropica

$3(7 \%)$

$3(7 \%)$

P. Ureae

Unspecified

\section{Exposure}

Exposed to Animals

$31(74 \%)$

Cats, Dogs, or Both

$29(69 \%)$

Sheep

$2(5 \%)$

Fish

$1(2 \%)$

Known Bite, Scratch, or Lick

$15(36 \%)$

Not Exposed

$7(17 \%)$

Unknown

$4(10 \%)$

\section{Valve affected}

Native Valve

$35(83 \%)$

Mitral

$16(38 \%)$

Aortic

$14(33 \%)$

Tricuspid

$4(10 \%)$

Pulmonary

$1(2 \%)$

Prosthetic Valve

$8(19 \%)$

Aortic

Mitral

Unknown

Dual valve affected

Native Mitral and Tricuspid

Native Tricuspid and Aortic prosthesis

\section{Treatment}

Antibiotics 


\section{Cureus}

Surgery

$18(43 \%)$

Outcome

Survived

$29(69 \%)$

Died

$11(26 \%)$

Unspecified

$2(5 \%)$

TABLE 2: Summary of literature review of all reported cases of definite Pasteurella infective endocarditis

IVD: intravenous drugs, P: Pasteurella, PMH: past medical history, SD: standard deviation, Spp: species

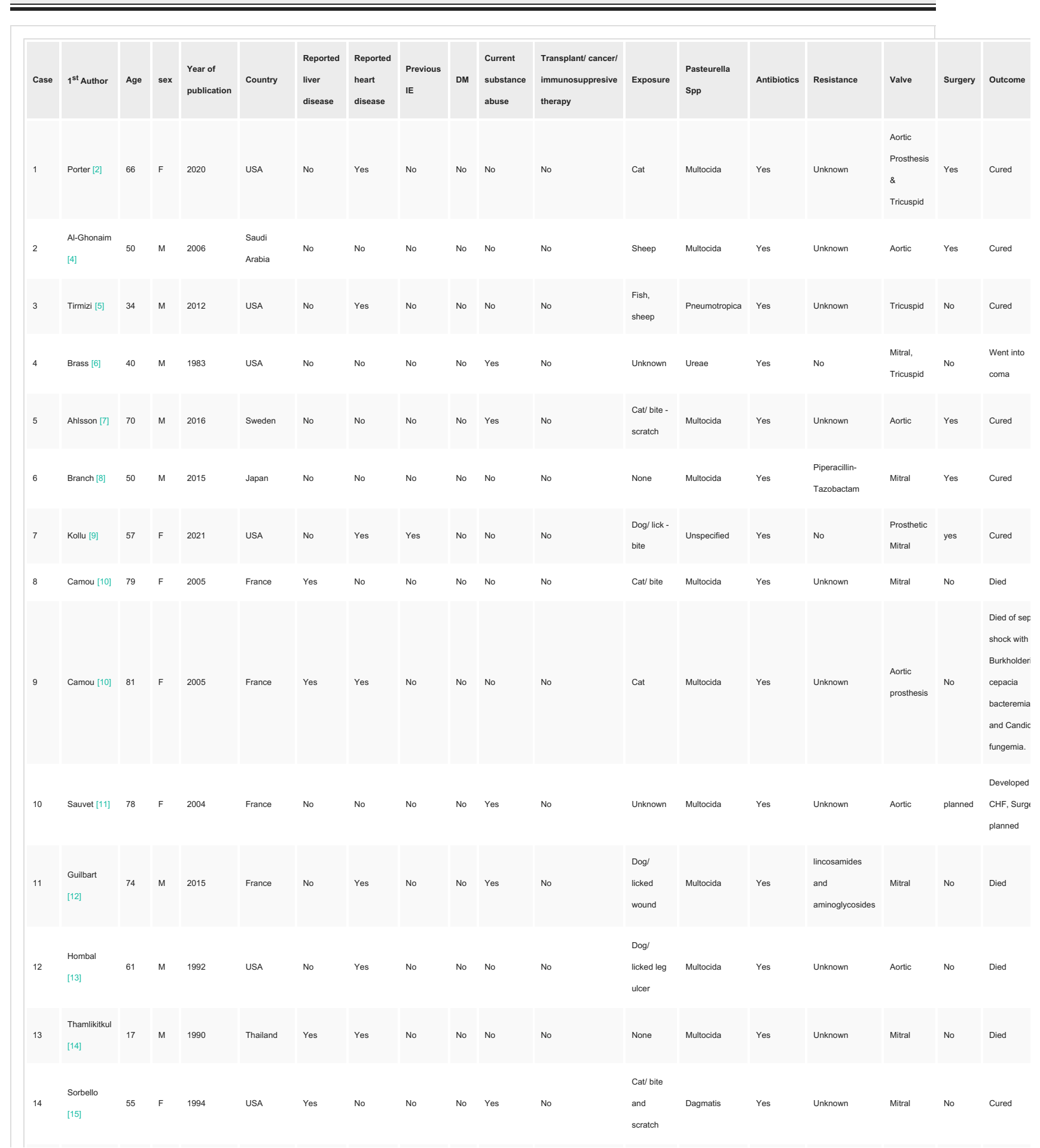




\section{Cureus}

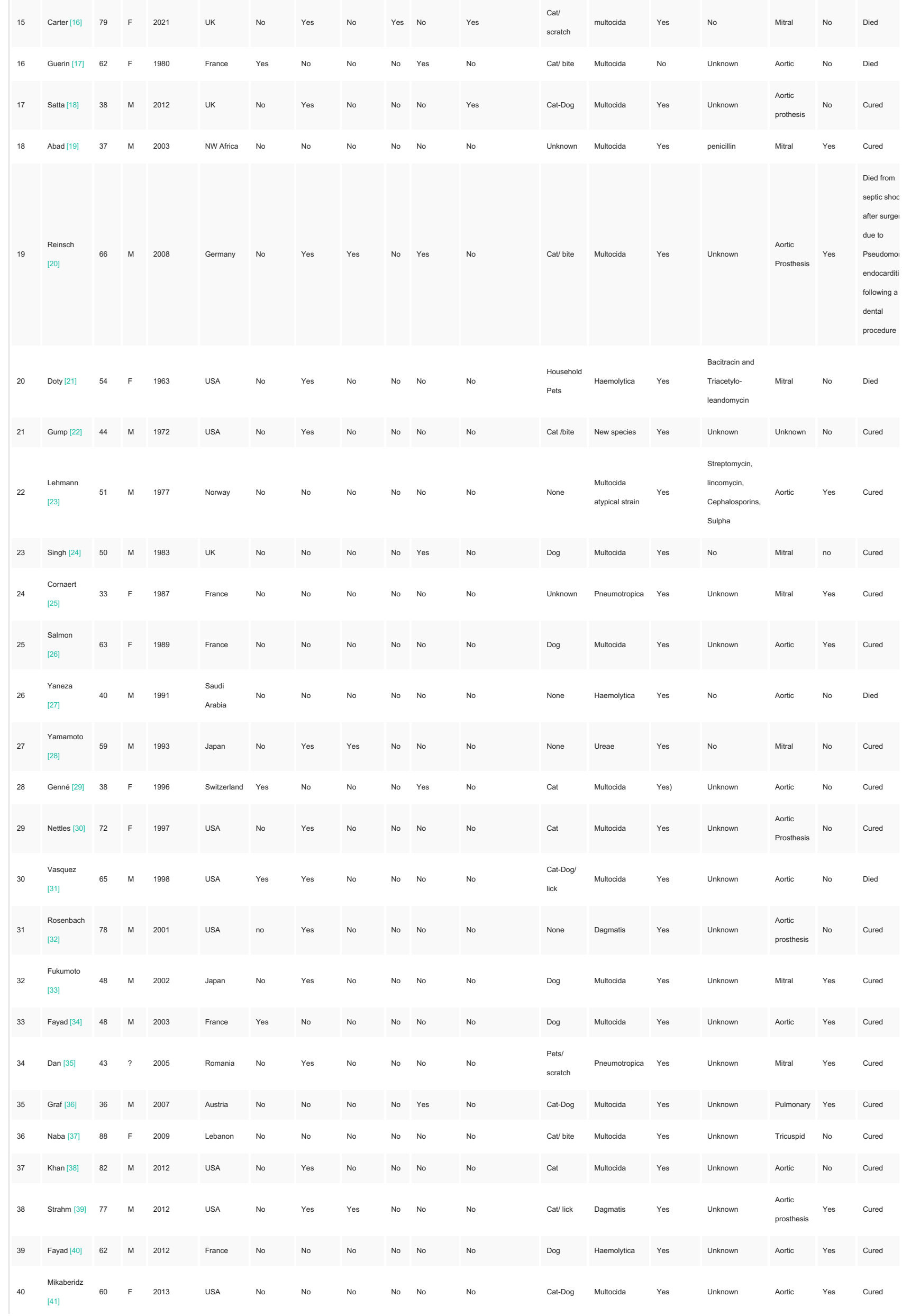




\section{Cureus}

criterion: evidence of endocardial involvement, and three minor criteria: fever, blood culture, and vascular phenomena (septic emboli to the brain).

Of 31 cases (74\%) who reported exposure to animals, 29 (94\%) had exposure to cats, dogs, or both. One had exposure to sheep [4], and another was exposed to fish and sheep [5]. Fifteen (48\%) had a known history of scratches, bites, or licking non-intact skin. Of all reported cases, seven (17\%) had no history of animal exposure. P. multocida has been isolated from the respiratory tract of healthy individuals who have frequent exposure to animals [1].

P. multocida was the most reported spp; 29 cases (69\%). 11 cases (26\%) had infection with non-multocida spp, including P. haemolytica (3), P. dagmatis (3). P. pneumotropica (3), and P. ureae (2).

The native mitral valve was the most affected (16 cases), followed by native aortic (14), prosthetic aortic (7), native tricuspid (4), native pulmonary (1), and prosthetic mitral (1) valves. Two cases reported dual valve infection $[2,6]$.

Risk factors included liver disease in seven (17\%), heart disease in 20 (48\%), prior endocarditis in four (10\%), substance abuse in 10 (24\%), diabetes mellitus in two (5\%), solid organ transplant/immunosuppressive therapy in one (2\%), and malignancy in one (2\%). However, Pasteurella IE has also been reported in six (14\%) healthy individuals. Immunocompromised patients are at higher risk of severe disease and complications such as sepsis, septic shock, and multiorgan failure [2,43]. A comprehensive review of 119 cases of $P$. multocida bacteremia reported comorbid conditions, such as chronic liver disease, diabetes mellitus, malignancy, and immunosuppressive therapy in $67 \%$ of patients, and the mortality rate was $31 \%$ at 30 days [43]. On multivariate analysis, having major comorbid conditions was the only factor associated with mortality (OR 2.78, 95\% CI 1.01-7.70: P-value 0.04) [43].

The overall mortality rate in previously reported cases of Pasteurella endocarditis was 26\% (11 cases), of which $64 \%$ (7 cases) had major comorbidities. A recent analysis of 32 cases of Pasteurella endocarditis demonstrated a statistically significant association between comorbid liver disease and mortality rate despite the low number of cases [2].

Our patient had a complex hospital course consisting of sepsis, septic shock requiring vasopressors, and acute hypoxemic respiratory failure secondary to cardiogenic pulmonary edema due to severe mitral regurgitation requiring intubation, resulting in death. Diabetes mellitus and liver cirrhosis were the predisposing conditions that led to severe invasive infection in this case.

Complications are not uncommon and related to bacteremia and valve vegetation. Reported complications included sepsis, septic emboli [8-9], congestive heart failure [2,10-11], septic shock [2,10,12-13,31], mycotic aneurysm [9,14], intracranial hemorrhage [14-15], septic arthritis [12,16], and osteomyelitis [15]. One case reported rhabdomyolysis and hearing loss [41].

There are no clear guidelines for treating Pasteurella endocarditis, and data are limited to a small number of case reports. All patients received antibiotics except one who died shortly after presentation [17]. Pasteurella spp is often susceptible to penicillin $[13,18]$. Broad-spectrum cephalosporins, piperacillin-tazobactam, and ampicillin-sulbactam can be used alternatively. One case of Pasteurella endocarditis of the prosthetic mitral valve reported successful treatment with six weeks of IV penicillin without surgery [9]. Tirmizi et al. reported successful treatment of $P$. pneumotropica endocarditis of the native tricuspid valve with six weeks of oral ciprofloxacin [5]. One case of P. multocida endocarditis of the aortic valve prosthesis had a penicillin allergy and was successfully treated with six weeks of IV ceftriaxone [18]. Two cases reported resistance to penicillin and piperacillin-tazobactam, respectively $[8,19]$. Duration of treatment was variable among reported cases, and it depended on the severity, course of the disease, co-existing conditions, and antibiotic susceptibility. Carter et al. recommended initial six weeks of antibiotics therapy based on the clinical response and the average duration in previously reported patients who were successfully treated with antibiotics only [16]. Of all 29 cases (69\%) who survived, 12 (41 \%) received antibiotics only without surgery. 
Of all reported cases, 18 (43\%) required surgery. Indications for surgical intervention were severe valvular insufficiency, persistent symptoms despite antibiotic therapy, and aortic root abscess. Seventeen out of 18 (94\%) cases who underwent surgery were cured while only one patient died four months after discharge due to septic shock secondary to Pseudomonas endocarditis of the native mitral and prosthetic aortic valves four weeks after a dental procedure [20]. Porter et al. suggested that surgery should be offered to all patients who have no absolute contraindications given the cure rate of $100 \%$ after surgical valve replacement [2]; however, their analysis did not consider the severity of illness, medical comorbidities, and indications for surgical intervention [16]. Moreover, they did not include the patient who died four months after surgery from Pseudomonas endocarditis [20]. Carter et al. suggested surgical intervention only if there is any indication, as with any case of other bacterial endocarditis [16]. The same study reported a patient with $P$. multocida endocarditis and septic arthritis successfully treated with antibiotics only despite his comorbidities.

There is no doubt that Pasteurella endocarditis is a rapidly progressive disease and is associated with high morbidity and mortality. It took approximately two weeks for our patient to develop complications following a cat scratch, one week from presentation to develop an increase in the valve vegetation size, and four weeks from presentation to death. He received a total duration of three weeks of antimicrobial therapy, but unfortunately, he was a poor surgical candidate due to significant comorbidities.

Due to its rarity, it is hard to conclude the proper management of Pasteurella endocarditis from the current literature. In the meantime, early recognition of the disease, interval echocardiograms to assess the vegetation size and possible complications, IV antibiotics, and early source control with surgical valve replacement for patients who have indications are the mainstay of treatment.

\section{Conclusions}

Infective endocarditis caused by Pasteurella spp is a rare though potentially serious and rapidly progressive disease with only 42 cases reported in the literature. It carries a high risk of morbidity and mortality, particularly in patients with comorbid conditions such as liver disease. Treatment is typically IV antibiotics, and surgery for source control should be considered on a case-by-case basis. Due to its rarity, further research is required to study the nature of disease progression, determine the appropriate duration of antimicrobial therapy, and identify the average time from symptom onset to surgery and its correlation with clinical outcomes.

\section{Additional Information \\ Disclosures}

Human subjects: Consent was obtained or waived by all participants in this study. Conflicts of interest: In compliance with the ICMJE uniform disclosure form, all authors declare the following: Payment/services info: All authors have declared that no financial support was received from any organization for the submitted work. Financial relationships: All authors have declared that they have no financial relationships at present or within the previous three years with any organizations that might have an interest in the submitted work. Other relationships: All authors have declared that there are no other relationships or activities that could appear to have influenced the submitted work.

\section{References}

1. Weber DJ, Wolfson JS, Swartz MN, Hooper DC: Pasteurella multocida infections. Report of 34 cases and review of the literature. Medicine (Baltimore). 1984, 63:133-54.

2. Porter RS, Hay CM: Pasteurella endocarditis: a case report and statistical analysis of the literature . Case Rep Infect Dis. 2020, 2020:8890211. 10.1155/2020/8890211

3. Li JS, Sexton DJ, Mick N, et al.: Proposed modifications to the Duke criteria for the diagnosis of infective endocarditis. Clin Infect Dis. 2000, 30:633-8. 10.1086/313753

4. Al-Ghonaim MA, Abba AA, Al-Nozha M: Endocarditis caused by Pasteurella multocida . Ann Saudi Med. 2006, 26:147-9. 10.5144/0256-4947.2006.147

5. Tirmizi A, Butt S, Molitorisz S: First reported case of Pasteurella pneumotropica tricuspid valve endocarditis. Int J Cardiol. 2012, 161:e44-5. 10.1016/j.ijcard.2012.04.007

6. Brass EP, Wray LM, McDuff T: Pasteurella ureae meningitis associated with endocarditis. Report of a case and review of the literature. Eur Neurol. 1983, 22:138-41. 10.1159/000115550

7. Ahlsson A, Friberg Ö, Källman J: An angry cat causing Pasteurella multocida endocarditis and aortic valve replacement-a case report. Int J Surg Case Rep. 2016, 24:91-3. 10.1016/j.ijscr.2016.05.021

8. Branch J, Kakutani T, Kuroda S, Shiba Y, Kitagawa I: Pasteurella multocida infective endocarditis: a possible link with primary upper respiratory tract infection. Intern Med. 2015, 54:3225-31. 10.2169/internalmedicine.54.4973

9. Kollu VS, Archibald L, Edwards M, Janelle JW, Hong KW, Kalyatanda G: Pasteurella cerebral mycotic aneurysm: a case report and review of the literature. Cureus. 2021, 13:e15312. 10.7759/cureus.15312

10. Camou F, Guisset O, Pereyre S, Gabinski C, Viallard JF, Mercié P, Pellegrin JL: Endocarditis due to Pasteurella sp. Two cases [Article in French]. Med Mal Infect. 2005, 35:556-9. 10.1016/j.medmal.2005.08.003

11. Sauvet F, Graffin B, Cremades S, Chemsi M, Leyral G, Paris JF, Carli P: Pasteurella multocida endocarditis revealed by inflammatory rachialgia [Article in French]. Rev Med Interne. 2004, 25:530-1. 10.1016/j.revmed.2004.03.003

12. Guilbart M, Zogheib E, Hchikat AH, et al.: Fatal multifocal Pasteurella multocida infection: a case report . BMC Res Notes. 2015, 8:287. 10.1186/s13104-015-1232-7 
13. Hombal SM, Dincsoy HP: Pasteurella multocida endocarditis. Am J Clin Pathol. 1992, 98:565-8. 10.1093/ajcp/98.6.565

14. Thamlikitkul V, Sangruchi T: Pasteurella multocida infective endocarditis: a case report. J Med Assoc Thai. 1990, 73:704-6.

15. Sorbello AF, O'Donnell J, Kaiser-Smith J, Fitzharris J, Shinkarow J, Doneson S: Infective endocarditis due to Pasteurella dagmatis: case report and review. Clin Infect Dis. 1994, 18:336-8. 10.1093/clinids/18.3.336

16. Carter E, Iroegbu U, Baig W, Sandoe JA: Pasteurella multocida endocarditis with septic arthritis: case report and review of the literature. EMJ Microbiol Infect Dis. 2021, [Epub]: 10.33590/emj/21-00129

17. Guerain JM, Segrestaa JM, Lamotte M: Pasteurella multocida endocarditis [Article in French]. Nouv Presse Med. 1980, 9:2735-6.

18. Satta G, Gorton RL, Kandil H: Prosthetic valve endocarditis caused by Pasteurella in a penicillin allergic patient: challenges in diagnosis and treatment. Infect Dis Rep. 2012, 4:e32. 10.4081/idr.2012.e32

19. Abad C, Cáceres JJ, Ferrer JM, González L, Alvarez F, Bordes A: Pasteurella multocida empyema in a patient after mitral valve replacement secondary to endocarditis [Article in Spanish]. An Med Interna. 2003, 20:4412.

20. Reinsch N, Plicht B, Lind A, et al.: Recurrent infective endocarditis with uncommon Gram-negative Pasteurella multocida and Pseudomonas aeruginosa: a case report. J Heart Valve Dis. 2008, 17:710-3.

21. Doty GL, Loomus GN, Wolf PL: Pasteurella endocarditis. N Engl J Med. 1963, 268:830-2. 10.1056/NEJM196304112681509

22. Gump DW, Holden RA: Endocarditis caused by a new species of Pasteurella . Ann Intern Med. 1972, 76:2758. 10.7326/0003-4819-76-2-275

23. Lehmann V, Knutsen SB, Ragnhildstveit E, Skagseth E, Solberg CO: Endocarditis caused by Pasteurella multocida. Scand J Infect Dis. 1977, 9:247-8. 10.3109/inf.1977.9.issue-3.19

24. Singh CP, Spurrell JR: Pasteurella multocida endocarditis. Br Med J (Clin Res Ed). 1983, 286:1862-3. 10.1136/bmj.286.6381.1862

25. Cornaert P, Masson P, Forzy G, Graux P, Camblin J, Dutoit A, Croccel L: Infectious endocarditis caused by rare germs. Review of the literature apropos of 2 cases [Article in French]. Ann Cardiol Angeiol (Paris). 1987, 36:87-93.

26. Salmon D, Fantin B, Bricaire F, Vilde JL, Pangon B, Ferand D: Endocarditis due to Pasteurella multocida with glomerulonephritis. Am J Med. 1989, 86:493. 10.1016/0002-9343(89)90356-2

27. Yaneza AL, Jivan H, Kumari P, Togoo MS: Pasteurella haemolytica endocarditis. J Infect. 1991, 23:65-7. 10.1016/0163-4453(91)94085-X

28. Yamamoto K, Ikeda U, Ogawa C, Fukazawa H, Eto M, Shimada K: Pasteurella ureae endocarditis. Intern Med. 1993, 32:872-4. 10.2169/internalmedicine.32.872

29. Genne D, Siegrist HH, Monnier P, Nobel M, Humair L, de Torrente A: Pasteurella multocida endocarditis: report of a case and review of the literature. Scand I Infect Dis. 1996, 28:95-7. 10.3109/00365549609027158

30. Nettles RE, Sexton DJ: Pasteurella multocida prosthetic valve endocarditis: case report and review . Clin Infect Dis. 1997, 25:920-1. 10.1086/597637

31. Vasquez JE, Ferguson DA Jr, Bin-Sagheer S, Myers JW, Ramsak A, Wilson MA, Sarubbi FA: Pasteurella multocida endocarditis: a molecular epidemiological study. Clin Infect Dis. 1998, 26:518-20. 10.1086/517105

32. Rosenbach KA, Poblete J, Larkin I: Prosthetic valve endocarditis caused by Pasteurella dagmatis . South Med J. 2001, 94:1033-5.

33. Fukumoto Y, Moriyama Y, Iguro Y, Toda R, Taira A: Pasteurella multocida endocarditis: report of a case . Surg Today. 2002, 32:513-5. 10.1007/s005950200087

34. Fayad G, Modine T, Mokhtari S, et al.: Pasteurella multocida aortic valve endocarditis: case report and literature review. J Heart Valve Dis. 2003, 12:261-3.

35. Dan M, Prisacariu C, Georgescu GI, Georgescu-Arsenescu C, Tinică G, Buiuc D: Subacute bacterial endocarditis due to Pasteurella pneumotropica. Case report [Article in Romanian]. Rev Med Chir Soc Med Nat Iasi. 2005, 109:743-5.

36. Graf S, Binder T, Heger M, Apfalter P, Simon N, Winkler S: Isolated endocarditis of the pulmonary valve caused by Pasteurella multocida. Infection. 2007, 35:43-5. 10.1007/s15010-007-5074-7

37. Naba MR, Araj GF, Kanafani ZA, Kanj SS: First case of Pasteurella multocida endocarditis of the tricuspid valve: a favorable outcome following medical treatment. Int J Infect Dis. 2009, 13:e267-9. 10.1016/j.ijid.2008.11.004

38. Khan MF, Movahed MR, Jung J: Pasteurella multocida endocarditis. J Heart Valve Dis. 2012, 21:260-2.

39. Strahm C, Goldenberger D, Gutmann M, Kuhnert P, Graber P: Prosthetic valve endocarditis caused by a Pasteurella dagmatis-like isolate originating from a patient's cat. J Clin Microbiol. 2012, 50:2818-9. 10.1128/JCM.00973-12

40. Fayad G, Modine T, Koussa M, Senneville E, Leroy O: First documented surgical case of human aortic valve endocarditis caused by Pasteurella haemolytica. J Heart Valve Dis. 2012, 21:139.

41. Mikaberidz N, Li EY, Taub CC: Pasteurella multocida infective endocarditis in an immunocompetent patient complicated by rhabdomyolysis and permanent hearing loss. J Cardiovasc Dis Res. 2013, 4:55-7. 10.1016/j.jcdr.2013.02.006

42. Yuji D, Tanaka M, Katayama I, Noguchi K: Pasteurella multocida infective endocarditis . J Heart Valve Dis. 2015, 24:778-9.

43. Chatelier E, Mahieu R, Hamel JF, et al.: Pasteurella bacteraemia: impact of comorbidities on outcome, based on a case series and literature review. Int J Infect Dis. 2020, 92:89-96. 10.1016/j.ijid.2020.01.003 